\title{
El dispositivo propietario. Elementos para una analítica de la propiedad
}

\author{
Franco Maximiliano Lagarrigue*
}

\section{Resumen}

El trabajo se propone reflexionar sobre la propiedad privada capitalista, aportando algunos elementos para una analítica de este objeto. La reflexión parte de la definición jurídica de propiedad hasta llegar a su definición como dispositivo. En el camino, se examinan los aportes de Marx, Althusser y Foucault. La hipótesis principal sostiene que la propiedad es algo más que un principio jurídico y un acto de apropiación de una relación social de explotación, es un dispositivo del modo de producción capitalista, a saber, una red de elementos heterogéneos articulados estratégicamente para producir un sujeto propietario.

El trabajo inicia con un breve diagnóstico acerca del estatuto teórico actual de la propiedad según la visión neoliberal hegemónica. Se destacan allí dos efectos ideológicos relevantes de esta perspectiva analítica para proceder a su crítica a través de las reflexiones de Marx, Althusser y Foucault. El recorrido comprende una revisión del derecho de propiedad como acto de apropiación del modo de producción capitalista (Marx); un análisis de los efectos ideológicos de ese acto de apropiación en los términos de producción (interpelación) de sujetos (Althusser); y la especificación del objeto propiedad como dispositivo que fabrica sujetos propietarios (Foucault). Para finalizar, el análisis destaca una característica primordial del dispositivo propietario: su condición de soporte anímico.

Palabras clave: Propiedad - Dispositivo - Marx - Althusser - Foucault.

\section{Abstract}

The owner device. Elements for an analytical of property

The study focuses on capitalist private property, providing some analytical elements of this object. Reflections start on the legal definition of property up to its definition as a device. On the way the contributions of Marx, Althusser and

\footnotetext{
* Universidad de Buenos Aires. Correo electrónico: maxilagarrigue@gmail.com. El presente escrito es resultado de la investigación doctoral realizada en la Facultad de Ciencias Sociales de la Universidad de Buenos Aires bajo el título "Sujeto y propiedad. Un estudio de sus vínculos en la teoría política de Thomas Hobbes y John Locke" y culminada en 2015. Debo mi agradecimiento a Susana Murillo y a su colectivo de trabajo por la formación y el acompañamiento brindados durante el proceso de investigación. Asimismo, agradezco la lectura rigurosa y las observaciones atentas realizadas por los evaluadores de la revista Leviathan.
} 
Foucault are examined. The main hypothesis is that the property is more than just a legal principle and an act of appropriation of a social relation of exploitation, is a device of the capitalist mode of production, namely, a network of heterogeneous elements articulated strategically to produce an owner subject.

The work begins with a brief analysis on the current theoretical status of the property according to the hegemonic neoliberal vision. It highlights two important ideological effects of this analytical perspective to proceed with its criticism through the reflections of Marx, Althusser and Foucault. The tour includes a review of property rights as an act of appropriation of capitalist mode of production (Marx); an analysis of the ideological effects of this act of appropriation in terms of production (interpellation) of subjects (Althusser); and a specification of property as a device that produces owners subjects (Foucault). Finally, the analysis highlights a key feature of the owner device: his condition of a "psychic support".

Keywords: Property - Device - Marx - Althusser - Foucault.

\section{Propiedad y neoliberalismo, dos puntos de partida}

La propiedad es uno de los conceptos centrales del pensamiento político moderno. A su notable protagonismo en los discursos jurídicos del siglo XV a la actualidad, le acompaña una igual disputa por el sentido y valor de este concepto. Así, tras la hegemonía del capitalismo liberal la propiedad fue confinada al valor jurídico-ideológico de un derecho exclusivo y excluyente al uso, goce y disposición de la cosa. Esta noción fue blanco de una crítica marxiana incomparable que demostró que el derecho de propiedad, lejos de ser un mero principio jurídico es, ante todo, un acto de apropiación de una relación social de producción (Engels y Marx 2005; Marx, 2009). No obstante, en el marco de la estrategia neoliberal de gobierno (dirigida especialmente a extinguir la crítica marxiana así como las múltiples resistencias contra el modo de acumulación capitalista) aquél sentido liberal de propiedad experimentó una mutación significativa a partir de la segunda mitad del siglo XX.

De manera paulatina se transitó de una concepción "metafísico-jurídica" de propiedad, que remitía este concepto al campo del derecho, y a su garante, el Estado, hacia 
una concepción "metafísico-culturalista", que convertía a la propiedad en una especie de radical antropológico con asiento último en el lenguaje. Pues, sostienen, dado que en todas las lenguas se distingue entre lo "mío" y lo "tuyo" es innegable que la propiedad privada es inherente al hombre, es primordial para la formación de su identidad y necesaria para la supervivencia del individuo (Pipes, 1999). El conjunto de trabajos teóricos que abonan a esta concepción fue proliferando con el correr de las últimas décadas del siglo XX y comienzos del XXI. Y se caracteriza, en lo fundamental, por retomar ciertos argumentos en favor del egoísmo intrínseco al hombre, de la escasez de bienes, y especialmente, de la utilidad económica que reporta la privatización de recursos, o cuando no, de la ventajas ecológicas del régimen de propiedad privada. ${ }^{1}$

Como indicamos, lo que tienen en común la mayoría de estos análisis es su inscripción, no homogénea, a la ideología neoliberal. En particular, y en lo que refiere al concepto de propiedad, sus autores promueven una reformulación de esta noción a partir del trasvase de la dimensión jurídica, en el que la tradición liberal la había depositado, hacia una dimensión cultural mayor que muestra la inherencia de este principio en los procesos económicos y sociales, y más importante aún, en el apuntalamiento de un tipo de sujeto. En dichos trabajos, pero especialmente en aquellos que indagan en los presupuestos políticos y antropológicos de la propiedad privada (Lepage, 1986 y Pipes, 1999), se observa un denodado esfuerzo por reenviar el problema de la propiedad (vale decir: de la privatización de lo común) al campo ontológico, donde este principio se convierte en condición de la existencia del hombre y en garantía de progreso para la civilización occidental (Hayek, 1981). Con ello, el análisis de la propiedad sufre un desplazamiento notable: de su vieja condición "superestructural" como regulador jurídico de las relaciones

\footnotetext{
1 Una recopilación de estos trabajos representaría una tarea ciclópea, no obstante es necesario mencionar alguno de ellos. Desde la disciplina económica se destacan los escritos de Plant (1934), Coase (1937), von Mises ([1949] 1986), Alchian (1965), Demsetz (1967), North (1973), Hayek (1981) y Landes (1998). En el campo jurídico, los trabajos de Honoré (1961), Epstein (1985), Munzer (1990) y Harris (2003). Mientras que, en el terreno de la filosofía política, caben mencionar los estudios de Lepage (1986), Nozick (1988) y Pipes (1999). La lista es extensa, una recopilación más reciente de los estudios sobre la propiedad desde un enfoque neoinstitucionalista se encuentra en Ann Davis (2015).
} 
de los hombres entre ellos y las cosas; a una dimensión ontológico-subjetiva, por la que la propiedad deviene ahora un modo de ser del hombre gracias al cual garantizar su existencia.

Ahora bien, a fin de justificar la propuesta analítica del presente trabajo, es importante fijar los dos supuestos de la propiedad neoliberal ya mencionados. Por un lado, la universalización metafísica de la propiedad; y por el otro, su incorporación al individuo como un garante ontológico. El primer aspecto, alude a la universalización de la propiedad como principio común a toda cultura, que desborda al orden jurídico y a su garante inmediato, el Estado, y que mienta cualquier tipo de relación exclusiva y excluyente entre los individuos y las cosas. Para decirlo en términos más claros: mientras en el liberalismo la propiedad era definida según el canónico Artículo 544 del Código Civil Francés de 1804 como "el derecho de gozar y disponer de las cosas de la manera más absoluta, con tal que no se haga un uso de las mismas prohibido por las leyes o los reglamentos"; en la concepción neoliberal, la propiedad es un elemento inherente al hombre, y es este individuo propietario el que modifica, bajo tal condición, las leyes o reglamentos. Con ello, el Estado y la ley se explicarían por la propiedad y no a la inversa, como sostenía la ilusión jurídico-liberal. $^{2}$ Este hecho es por demás significativo pues, ya no se trata ni de las "relaciones de propiedad o de producción" (Marx), ni del "derecho de propiedad" que asegura y legitima la exclusión y el intercambio, sino de la propiedad en un sentido más amplio: un concepto puro que anida en la naturaleza humana y cuya evidencia radica en la imposición del pronombre posesivo "mío" presente en toda cultura. ${ }^{3}$

Ante un efecto ideológico de este tenor el trabajo propone, a continuación, una breve revisión del concepto de propiedad en Marx, con el objetivo de resituar a esta noción

\footnotetext{
${ }^{2}$ Así se expresa Pipes: “Porque decir que 'somos dueños de nosotros mismos', es decir que somos nuestra propia 'propiedad', es equivalente a decir que tenemos la libertad de disponer de nosotros mismos, que es el significado de nuestra libertad" (Pipes, 1999: 61). Sin detenernos aquí en la discusión que acarrea el postulado de la autopropiedad enunciado por Pipes (al respecto, véase Pateman, 2002), es pertinente advertir cómo la propiedad se subjetiva en términos puramente lingüísticos.

${ }^{3}$ Este supuesto, constituye una de las principales tesis que el trabajo de Richard Pipes se propone defender: “[...] defenderemos la tesis de que el deseo de adquirir es universal entre los seres humanos y, también, entre los animales, que es mucho más que el deseo de controlar objetos físicos y que está íntimamente relacionada con la personalidad humana, a estimular un sentido de identidad y competencia" (Pipes, 1999: 96).
} 
en la totalidad del modo de producción capitalista, devolviéndole la gravedad que, a nuestro juicio, la teoría neoliberal encubre en favor de un culturalismo abstracto y fetichizante.

No obstante, y antes de dar este paso, es menester decir algo más sobre el segundo supuesto de la propiedad neoliberal; esto es, sobre la profunda ligazón que ciertos teóricos establecen entre propiedad y sujeto. ${ }^{4}$ En efecto, algunos miembros de la denominada Escuela Austríaca, vieron en la propiedad (como en la desigualdad y en la competencia) una especie de a priori del sujeto-empresa, vale decir, una condición de posibilidad para la experiencia del mercado. Y es que, a su juicio, sin la propiedad, se desvanecería el carácter trascendental del individuo, peligrando con ello su autonomía y libertad (von Mises, 1986; Hayek, 1981y 1990). En línea con estas ideas, los economistas de la Escuela de Chicago, Theodore Schultz (1961) y Gary Becker (1962) observaron, en el marco de su teoría del "capital humano", que la propiedad es un atributo esencial del hombre; garantía de su integridad física y espiritual. Gracias a ella el individuo no sólo se apropia de lo necesario para la subsistencia, sino también del sí mismo (de su cuerpo, habilidades y capacidades: activos económicos) capaz de fortalecerlo e impulsarlo como un "empresario de sí". Los argumentos esgrimidos en favor de este acto de apropiación solipsista recorren desde enunciados biologicistas, como la existencia de un instinto de territorialidad común a todas las especies (apoyada en los trabajos de Eliot Howard, Ernst Beaglehole y Konrad Lorenz), a postulados psicologistas, que señalan la importancia de la práctica de adquisición para la formación de la persona (William James), pasando por algunos trabajos antropológicos que desacreditan la tesis de Lewis Morgan (no casualmente, seguida por Marx y Engels) respecto a la existencia de una propiedad colectiva en las sociedades primitivas (los trabajos de Robert Lowie, Frank Speck y Edward Adamson Hoebel) (véase Pipes, 1999). En suma, la posición neoliberal sostiene que la propiedad privada es inescindible del sujeto, y que es por este sujeto universal (egoísta, territorial, posesivo, etc.) que se prueba la existencia de

\footnotetext{
${ }^{4}$ La relación entre ownership y property ha sido planteada incluso en términos de una extraña paradoja (Singer, 2000), sin advertir el fondo que las comunica (la producción de un individuo propietario en el capitalismo) y su rearticulación estratégica bajo la racionalidad neoliberal.
} 


\section{Leviathan | Cuadernos de Investigación Política}

LAGARRIGUE, F. M. “El dispositivo propietario. Elementos para una analítica de la propiedad"

la propiedad. De manera que la propiedad ya no se deduce del artificio del Estado y del universo de los derechos, sino de una estructura trascendental del sujeto que encuentra en la propiedad su fundamento así como la garantía de su conservación y libertad. ${ }^{5}$

Este otro aspecto de la teoría neoliberal de la propiedad (la justificación de la propiedad a partir de la producción de un sujeto) obliga a una revisión crítica de los modos en los que dicha subjetividad propietaria se produce. Es decir, que una analítica de la propiedad requiere no sólo del estudio de las relaciones de producción sobre las que se genera el acto material de apropiación, sino también del examen de las técnicas involucradas en la producción de un sujeto propietario como efecto y vector de un entramado de saber-poder, o más específicamente de lo que se denominará en este trabajo un "dispositivo propietario". En este sentido es que se justificará en los próximos apartados la utilización de algunos conceptos de Althusser y Foucault. Con todo, y antes de avanzar en este bloque, conviene revisitar la crítica de Marx a la propiedad capitalista liberal, con el objetivo de emplazar su problemática en el nivel de las prácticas históricas y de los modos de producción.

\footnotetext{
${ }^{5}$ Muchos son los trabajos que a lo largo del siglo XX alertaron sobre la profunda copertenencia entre sujeto y propiedad. Entre ellos, puede mencionarse el escrito precursor de Tawney (1920) sobre el espíritu adquisitivo inglés; el estudio de Macpherson (1962) sobre el individualismo posesivo subyacente a la ideología liberal; la metafísica de la propiation de Derrida (2007); la disyuntiva del tener o el ser de Fromm (2007); la génesis del "individuo-en-el-mundo" de Dumont (1987); y más recientemente, la ontología del proprium que se tensa con la communitas ensayada por Esposito (2003); los estudios sobre la autoenunciación del sujeto de Balibar (2006); o la genealogía del individuo hipermoderno de Castel (2010). En cierta forma, todos estos trabajos señalan la necesidad de avanzar en un análisis de la subjetividad dilucidando los principios ontológicos que constituyen al propietario de la modernidad capitalista y sus efectos sobre el presente. A este respecto, podría sugerirse a modo de hipótesis que el giro metafísico-culturalista de la teoría de la propiedad trajo consigo una reorientación de los estudios sobre dicha noción dirigida ahora a la dimensión subjetiva de la misma.
} 


\title{
1. La propiedad en Marx, o el acto de apropiación de un modo de producción
}

Una de las primeras dificultades que reviste el estudio de la propiedad es la maraña de prácticas sociales a los que este concepto reenvía. Aunque los discursos jurídico liberales de comienzos del siglo XVII se esforzaron por circunscribir la propiedad en el campo jurídico del derecho, sabido es, gracias a la crítica de Marx, que la propiedad comprende también y fundamentalmente una serie de relaciones económicas o "relaciones de propiedad" que cambian según el modo de producción histórico. A este respecto, ni siquiera la famosa crítica de Joseph Proudhon pudo salir indemne de la denuncia de Marx. Pues, si bien el primero dejó muy en claro en ¿Qué es la propiedad? (1840) que la condición de este derecho es ni más ni menos que el robo (1983: 29); para Marx, Proudhon jamás pudo escapar a la ilusión jurídico liberal que hacía del derecho de propiedad el referente de la riqueza o de la miseria. ${ }^{6}$ De aquí que en Miseria de la filosofía (1847), Marx sentencie, contra Proudhon:

\begin{abstract}
"En cada época histórica la propiedad se ha desarrollado de modo distinto y bajo una serie de relaciones sociales totalmente diferentes. Por lo tanto, definir la propiedad burguesa no es otra cosa que exponer todas las relaciones sociales de la producción burguesa. Querer definir la propiedad como una relación independiente, una categoría aparte y una idea abstracta y eterna, no es más que una ilusión metafísica y jurídica" (Marx, 1970: 104).
\end{abstract}

Para Marx, al menos para el Marx de 1844 en adelante, la propiedad privada sólo puede ser entendida como un efecto de relaciones sociales. $Y$ en el caso particular de la propiedad privada capitalista la relación social que la define es la de explotador-explotado bajo la forma de capital y trabajo asalariado. Este es el sentido en el que el análisis de Marx

\footnotetext{
${ }^{6}$ El problema de la propiedad es abordado por Marx de manera temprana, y atraviesa como un hilo rojo todos sus escritos. Así, el postulado de la propiedad como robo ("La Propriéte', c'est le vol") es reafirmado por Marx en 1842, en sus artículos "Los debates sobre la Ley acerca del Robo de Leña". Marx, situado en el campo ideológico del liberalismo, no dudará en denunciar el carácter metafísico y lógicamente contradictorio del absolutismo de la propiedad privada moderna por menoscabar los derechos consuetudinarios de los pobres: "Si toda lesión de la propiedad, sin diferencia, sin determinación más precisa, es robo, ¿no sería toda propiedad privada un robo? ¿Con mi propiedad privada no excluyo a todo terreno de esa propiedad, no lesiono, pues, su derecho de propiedad?"(2007: 30).
} 
avanza en los Manuscritos económico-filosóficos de 1844 y en la Ideología alemana de 1845. En esta última obra, en particular, Marx (junto a Engels) denuncia las formas fantasmales que el derecho burgués produce y que sirven a la legitimación de la explotación capitalista, como son la propiedad privada y el contrato. Para esto, propone un movimiento analítico crucial: arranca el concepto de propiedad de su encuadre jurídico (que lo equipara al derecho de propiedad privada) para llevarlo al terreno de los modos de producción. Esto es, sitúa el problema de la propiedad en el horizonte histórico-social de las relaciones de producción y del desarrollo de las fuerzas productivas refutando, con ello, los dos postulados centrales de la ideología jurídico liberal. Por un lado, aquel que sostiene que la propiedad es un mero título jurídico; y por otro, aquel afirma que dicho título jurídico es la expresión de la libre voluntad del individuo sobre las cosas. Contra el primer postulado, Marx prueba que la propiedad nace del trabajo como acto de apropiación de los medios necesarios para la producción y reproducción de la vida (Engels y Marx, 2005: 19-20, 28-30 y 79-80). Y, contra el segundo, que los títulos de propiedad no dependen de la voluntad individual, sino de las relaciones de producción y del desarrollo de las fuerzas productivas sin los cuales el uso y disposición de las cosas (el jus utendi et abutendi) no es más que una quimera (2005: 72). En uno de los párrafos más elocuentes del texto afirma:

"El derecho privado proclama las relaciones de propiedad existentes como el resultado de la voluntad general. El mismo jus utendi et abutendi expresa, de una parte, el hecho de que la propiedad ya no guarda la menor relación con la comunidad y, de otra parte, la ilusión de que la misma propiedad privada descansa sobre la mera voluntad privada, como el derecho a disponer arbitrariamente de la cosa. En la práctica, el abuti tropieza con limitaciones económicas muy determinadas y concretas para el propietario privado, sino quiere que su propiedad, y con ella su jus abutendi, pasen a otras manos, puesto que la cosa no es tal cosa simplemente en relación con su voluntad, sino que solamente se convierte en verdadera propiedad en el comercio e independientemente del derecho a una cosa [...] Esta ilusión jurídica, que reduce el derecho a la mera voluntad, conduce, necesariamente, en el desarrollo ulterior de la propiedad, al resultado de que una persona pueda ostentar un título jurídico a una cosa sin llegar a tener realmente ésta" (2005: 73-74. Cursiva propia).

A fuerza de resumir las proposiciones centrales de Ideología alemana sobre la propiedad, digamos que el texto aporta dos premisas analíticas fundamentales para el tratamiento de esta problemática: 1) Que la propiedad es, ante todo, un acto de 
apropiación; y 2) que todo acto de apropiación está determinado históricamente por el modo de producción. Sobre ambas premisas Marx se explaya en los cuadernos preparatorios de El capital, los Grundrisse (1857-1858), haciendo un análisis general de las relaciones de propiedad y de los modos de producción que antecedieron al modo de producción capitalista. Se trata del borrador titulado Formas que preceden a la producción capitalista, y cuyo objetivo es, por un lado, explicar cuáles son los presupuestos históricos "para que encontremos al trabajador como trabajador libre, como capacidad de trabajo puramente subjetiva, desprovista de objetividad, enfrentados a las condiciones objetivas de producción como a su no propiedad, como a propiedad ajena, como valor que es para sí mismo". Y por otro, el de responder al interrogante sobre "qué condiciones son necesarias para que el trabajador encuentre frente a sí un capital" (Marx, 2009: 459). Por tanto, se trata de explicar cómo tuvo lugar este enfrenamiento o relación de ajenidad entre el trabajador y sus medios de subsistencia, habida cuenta que en las sociedades precapitalistas tal oposición era inexistente. Pues bien, para explicar esto Marx se vale de las dos premisas antes mencionadas. Por un lado, clarifica el tipo de apropiación de las sociedades pre-capitalistas; y, por el otro, analiza las relaciones sociales de producción que, según el grado de desarrollo de las fuerzas productivas, las forman. Esto le permitirá mostrar, además, que el derecho de propiedad capitalista es un principio jurídico que legitima (a la vez que deniega) el acto de apropiación de los medios de producción basado en la relación de explotación. Pero para entender mejor el descuadre que Marx realiza de la concepción jurídico liberal de propiedad, es menester precisar analíticamente de qué se trata la apropiación, las relaciones de producción, y las relaciones jurídicas de propiedad.

Sobre la base del estudio de Etienne Balibar en Para leer El capital (2010), titulado "Acerca de los conceptos fundamentales del materialismo histórico", Óscar Correas (2000) propone distinguir para una lectura del borrador Formas tres tipos de relaciones de propiedad. Por un lado, 1) las relaciones de apropiación, es decir, la relación del productor con los medios de producción: relación que permite poner en acción los medios, o sea, hacer apropiación real. Por el otro, 2) las relaciones de propiedad o relación social de 
producción, esto es, la relación entre los productores que se funda en la relación anterior: en el capitalismo sólo el capitalista hace apropiación real del medio de producción al explotar al trabajador. En este punto, Correas corrige a Balibar y precisa algo importante: en el modo de producción capitalista el capitalista no explota por ser dueño (por tener derecho al medio de producción), sino que es dueño porque explota, esto es: porque es el único que puede hacer apropiación efectiva extrayendo plusvalía (Correas, 2003: 208-209). Por último, 3) las relaciones jurídicas de propiedad, es decir, el orden jurídico de la propiedad en el derecho capitalista; simplificando: los contratos y la propiedad como un jus utendi et abutendi.

Las dos primeras nomenclaturas remiten, cada una, a las premisas analíticas de Ideología alemana. Así la relación de apropiación es el acto por medio del cual se hace efectiva la apropiación del medio de producción; mientras que las relaciones de propiedad, son el vínculo que se establece entre los productores en dicha apropiación. Por su parte, el último tipo de relación refiere a la expresión ideológica que asumen las relaciones anteriores en el modo de producción capitalista. Vale aclarar que esta última relación puede cambiar según el modo de producción del que se trate. Así, y por ejemplo, en sociedades como la romana arcaica, predominaría una relación de tipo político-militar más que jurídica, y esta relación condicionaría la relación de apropiación y las relaciones de producción, y no a la inversa, sin requerir, en principio, de la ilusión del derecho para garantizar la extracción del excedente: el esclavo hace apropiación real por estar sometido (política y militarmente) a un ciudadano que busca conservar la polis o civitas y su posición política dentro de ella; mientras que, en el capitalismo, el capitalista hace apropiación real al explotar (económicamente) al trabajador con fines estrictamente acumulativos, conservando su posición económica.

Como vemos la clave de la explicación del enfrentamiento entre el trabajador y el medio de producción radica en determinar qué ocurre con las dos primeras relaciones, y qué papel ocupa el tercer tipo de relación en las formaciones anteriores. En este sentido, Marx avanza de manera meticulosa en el texto Formas aludiendo al primer tipo de relación 
(las de apropiación) en los términos de un "comportamiento" (Verhalten). Esta inflexión semántica no es (y nunca lo es en Marx) una cuestión meramente lingüística, porque decir que el acto de apropiación en dichas sociedades reviste la forma del comportamiento y no del enfrentamiento (o "contraposición": Gegenüberstellung), es decir que los hombres están "unidos" a los medios de producción como a una "naturaleza inorgánica de su subjetividad", y que el acto físico de apropiación sirve a la reproducción del productor como miembro de la entidad comunitaria (Marx, 2009: 433-434). ${ }^{7}$ Lo contrario de lo que sucede en el modo de producción capitalista, donde el trabajador es un apéndice de los medios de producción que lo reproducen como trabajador asalariado. A lo largo del texto Formas Marx muestra que en las sociedades tribales, así como en las sociedades antiguas, esclavistas y feudales, los productores no se enfrentan a los medios de producción como a algo completamente ajeno y devorador, sino que se comportan hacia ellos en tanto son la condición inmediata para la subsistencia y conservación de la comunidad. A la inversa de lo que ocurre en la sociedad capitalista, donde es la subsistencia (el trabajo libre) la que garantiza la reproducción de los medios (el salario y plusvalor) para la acumulación de capital. De esto mismo se sigue que en las formaciones pre-capitalista el excedente se presenta como un resultado de la apropiación efectiva y no la apropiación efectiva como un resultado del excedente (ibíd.: 456-457). La razón de ello estriba en el tipo de relación de producción, es decir, en la segunda relación antes mencionada.

En efecto, mientras en las sociedades pre-capitalistas la apropiación efectiva se produce por relaciones de producción basadas principalmente en formas de coacción extraeconómica (cultural, religiosa, política y/o militar); en el modo de producción capitalista, las relaciones de producción se sostienen, fundamentalmente, a través de la coacción económica. Esto quiere decir que la apropiación real que realiza el capitalista del medio de producción implica, necesariamente, la extracción del plusvalor del trabajador y la separación de sus condiciones objetivas. En otras palabras: en el capitalismo, y sólo en él,

\footnotetext{
7 Agradezco a Pablo Nocera las aclaraciones semánticas sobre los conceptos de "comportamiento" y de "contraposición" en la obra de Marx.
} 
la apropiación real se efectúa mediante la relación de explotación del capitalista con el trabajador. Es cierto que en Formas Marx señala que la génesis extraeconómica de la propiedad capitalista es la génesis histórica de la economía burguesa, apuntando allí las líneas rectoras del famoso capítulo XXIV de El capital sobre la llamada acumulación originaria (2009: 470). No obstante, y con posterioridad (o mejor dicho, en paralelo) a este proceso, una vez separado el productor directo de sus condiciones objetivas (el polo trabajo y el polo capital) los trabajadores se ven obligados a entregar su plustrabajo a la única clase capaz de realizar ahora la apropiación efectiva de los medios de producción: la capitalista. Que, vale recordar, no explota por poseer los medios de producción (por tener el derecho a ellos) sino que los posee porque explota; y explota, porque es la única clase capaz de hacer la apropiación efectiva de los medios de producción, dado que sólo ella tiene el control técnico y la dirección del proceso de trabajo (Balibar, 2010: 240). Es aquí entonces que el tercer tipo de relación (las relaciones jurídicas de propiedad) juega un papel central, porque sirviéndose de las figuras abstractas del contrato y la propiedad, permite vehiculizar las relaciones de intercambio, garantizando la apropiación efectiva del capitalista. Si bien este tipo de coacción ideológico-jurídica adquiere una función destacada en el modo de producción capitalista, respecto a formaciones sociales anteriores (la antigua y la feudal) en las que predomina la coacción física; lo cierto es que las relaciones político-militares no desaparecen, sino que se convierten en la condición de posibilidad (histórica, latente y manifiesta) de las relaciones jurídico-ideológicas. Con todo, sólo en el capitalismo las relaciones jurídicas de propiedad se confunden con las relaciones de apropiación y de producción, enmascarando el acto de explotación. De esta forma es como Marx lo dice en El capital:

"Las mercancías no pueden ir por sí solas al mercado ni intercambiarse ellas mismas. Tenemos, pues, que volver la mirada hacia sus custodios, los poseedores de mercancías. Las mercancías son cosas y, por tanto, no oponen resistencia al hombre. Si ellas se niegan a que las tome, éste puede recurrir a la violencia o, en otras palabras, apoderarse de ellas. Para vincular esas cosas entre sí como mercancías, los custodios de las mismas deben relacionarse mutuamente como personas cuya voluntad reside en dichos objetos, de tal suerte que el uno, sólo con acuerdo de la voluntad del otro, o sea mediante un acto voluntario común a ambos, va a apropiarse de la mercancía ajena al enajenar la propia. Los dos, por consiguiente, deben reconocerse uno al otro como propietarios privados. Esta relación jurídica, cuya forma 
es el contrato -legalmente formulado o no-, es una relación entre voluntades en la que se refleja la relación económica. El contenido de tal relación jurídica o entre voluntades queda dado por la relación económica misma" (Marx, 2002: 103).

Las relaciones jurídico-ideológicas son, siguiendo a Marx, las máscaras que adoptan las personas para realizar el acto de intercambio en la forma del contrato entre voluntades que son propietarias privadas de sus mercancías. En este punto, vale la explicación de Sohn-Rethel: "El concepto de propiedad, en sí mismo, no es más que una conceptualización de la necesidad fáctica de mantener separados el uso y el intercambio. La necesidad de eximir del uso a los objetos que intervienen en el intercambio es un hecho empírico; sin él, el intercambio es imposible" (1980: 45). Siguiendo a Sohn-Rethel, el hecho fáctico es la obligación del trabajador de vender su fuerza de trabajo a cambio de un salario; no el acto abstracto de intercambiar voluntariamente su trabajo como si fuera una mercancía o propiedad cualquiera. Lo que sucede es que la abstracción jurídica del derecho de propiedad introduce aquí una igualdad formal entre elementos constitutivamente desiguales desde el punto de vista de las relaciones de apropiación y de propiedad; pues, no es lo mismo la propiedad de los medios de producción que la propiedad de la fuerza de trabajo, así como no es lo mismo ser el apropiador real de los medios de producción que ser un mero apéndice de los mismos. Este desajuste entre relaciones jurídicas y relaciones económicas revela que el orden jurídico capitalista tiene por función principal explicar, sostener y legitimar el hecho empírico (histórico, y sin dudas, traumático) de la separación del trabajador de los medios de producción. En este sentido, las relaciones jurídicas no serían más que los vínculos abstractos que unirían al trabajador con el capital en los términos, igualmente abstractos, de persona, propiedad y contrato. De esta forma, la separación del trabajador de los medios de producción se explicaría y obturaría apelando al universalismo del derecho, que traduce la coacción física en actos voluntarios; la explotación de clases en intercambio entre personas; y la apropiación real, en un título jurídico de propiedad sobre todo lo que los medios de producción y el trabajo-mercancía producen, que sería una consecuencia jurídica de todo lo anterior: de la voluntad de las partes y del contrato celebrado. 
Sin embargo, por más abstractas que se presenten las relaciones jurídicas de propiedad, ellas poseen un espesor histórico que excede en mucho a los de la modernidad capitalista (gustosa de presentarse como el puro presente). La institución de la que se sirvió en buena medida el Estado moderno para el ejercicio de la coacción jurídico-ideológica fue la institución del derecho mercantil romano, extrapolada y adaptada a las necesidades históricas del modo de producción capitalista. Del derecho romano, no sólo se extrapolaron y resignificaron figuras como las del contrato y el dominium, sino también la institución de los frutos y productos (Correas, 2003). Para esta última, lo producido por el esclavo, por la finca del ciudadano, o por el territorio del conquistador pertenecía: o al propietario del esclavo, o al ciudadano dueño de la finca, o al ejército que lo ocupó. No obstante, una pieza jurídica como ésta es de difícil encastre en el modo de producción moderno, porque siguiendo su estricta lógica, ¿a quién pertenecería entonces el producto del trabajador libre: al capitalista o al trabajador asalariado? Sabido es que en las sociedades antiguas las relaciones político-militares convertían al esclavo en el productor "natural" del polites o quirites; pero ¿qué sucede cuando el trabajador es un asalariado por coacción económica? Aquí la solución jurídica reposa en el desplazamiento de la teoría de los frutos y productos de su marco político-militar al marco jurídico-ideológica que parte del derecho de propiedad considerado en su universalidad y abstracción. Pues, si lo que el capitalista adquiere del trabajador es su fuerza de trabajo como propiedad-mercancía exclusiva y excluyente (tan exclusiva y excluyente como lo es para el derecho el medio de producción del capitalista) entonces todo lo que las propiedades producen (el plusvalor) corresponderían al titular jurídico que voluntariamente y por contrato las adquirió. Esto, claro está, en el plano jurídico. El trabajo de Marx en Formas consiste, como vimos, en desmontar esta fantasía jurídica de la propiedad, mostrando que el concepto de propiedad lejos de aludir a una categoría abstracta de la que emanan las relaciones sociales de intercambio, refiere al acto de apropiación concreto de relaciones sociales de producción concretas desplegadas en un modo de producción concreto, vale decir, histórico. 


\section{Autonomía relativa, sobredeterminación y Aparatos ideológicos de Estado. De las relaciones de producción al sujeto en la teoría de Althusser}

Ahora bien, afirmar que el derecho de propiedad es un efecto del acto de apropiación y de las relaciones de propiedad en un modo de producción, no es igual a decir que el derecho de propiedad es una mera ilusión jurídica de un orden superestructural. Las relaciones jurídicas de propiedad, no sólo poseen consistencia y eficacia específica, sino que además han sido y son el territorio de múltiples luchas por la hegemonía del modo de producción capitalista y sus resistencias. En este sentido es que es pertinente seguir a Althusser (1988 y 2010) y entender que las relaciones jurídicas guardan una "autonomía relativa" respecto de la "causalidad estructural" del modo de producción capitalista. Ello quiere decir, que aunque las relaciones jurídicas de propiedad actúen como un efecto "ilusorio" de las relaciones de apropiación y de propiedad "reales", éstas guardan una especificidad o autonomía que, como tal, afecta la contradicción fundamental (más nunca simple) entre capital y trabajo. Pues bien, al conjunto de efectos de la superestructura, así como de la historia interna y externa de un país, que determinan específicamente la contradicción estructural de un modo de producción en su juego activo y reactivo, Althusser lo llama sobredeterminación (2010: 81). Este concepto teórico, que Althusser recoge de Freud, es de suma relevancia para una analítica de la propiedad, ya que permite reconocer la función específica de las relaciones jurídicas de propiedad y su gravitación histórica en distintos contextos, así como también los efectos de las múltiples combinaciones con otros factores del modo de producción capitalista.

Por su parte, en "Ideología y aparatos ideológicos de Estado" (1970) Althusser amplía y profundiza el análisis acerca de la relación entre estructura y superestructura en el capitalismo, adoptando para ello un punto de vista no ya "descriptivo" de la tópica basesuperestructura, sino "reproductivo". Se propone allí analizar el funcionamiento productivo de la superestructura para la reproducción de las condiciones de producción capitalista (de 
las fuerzas productivas y de las relaciones de producción) "superando" de esta forma la etapa descriptiva que colocaba a la superestructura como una fase de ejecución y represión en manos de la clase dominante. Aunque Althusser no niega esta función esencial del aparato de Estado, su objetivo es ir más allá de esta descripción y atender a una realidad que se manifiesta junto a ella y a la que denomina aparatos ideológicos de Estado [de aquí en más AIE] (1988: 24). Los AIE son el conjunto de "instituciones distintas y especializadas" que, a diferencia del aparato (represivo) de Estado no "funciona masivamente con la represión mediante la violencia, y sólo secundariamente con la ideología"; sino que "funcionan masivamente con la ideología como forma predominante pero utilizan secundariamente, y en situaciones límite, una represión muy atenuada, disimulada, es decir simbólica." "Así - explica Althusser - la escuela y las iglesias 'adiestran' con métodos apropiados (sanciones, exclusiones, selección, etc.) no sólo a sus oficiantes sino a su grey" (1988: 26-27). No obstante esta distinción, entre el funcionamiento del aparato (represivo) de Estado (en lo sucesivo AE) y el de los AIE existen, para Althusser, múltiples combinaciones explícitas o tácitas entre la acción del AE y los AIE. Como sostiene: "ninguna clase puede tener en sus manos el poder de Estado en forma duradera sin ejercer al mismo tiempo su hegemonía sobre y en los aparatos ideológicos de Estado" (1988: 28). De aquí, que los AIE sean tanto el objeto como el lugar de la lucha de clases. Empero, y al mismo tiempo, gracias al aparato represivo de Estado se aseguran por la fuerza las condiciones políticas para el funcionamiento de los AIE que, asimismo, aseguran "en gran parte" la reproducción de las relaciones de producción mediante el uso masivo de la ideología ¿Cómo sucede esto?

Partiendo de la tesis que sostiene que la ideología tiene una existencia material, Althusser argumenta que la “ideología existente en un aparato ideológico material prescribe prácticas materiales reguladas por un ritual material, prácticas éstas que existen en los actos materiales de un sujeto que actúa con toda conciencia según su creencia" (1988: 51). Denomina a esta prescripción ideológica “interpelación”, y en ella encuentra el mecanismo fundamental de los AIE. Según una tesis central que dice que "la ideología interpela a los individuos como sujetos", los AIE son los encargados de interpelar a los 
individuos como sujetos (autores, libres, racionales y responsables) sujetados al Sujeto (a la totalidad social). Su funcionamiento consiste en reconocer al individuo como sujeto (único, inconfundible e irremplazable) asignándole un lugar y un papel en los rituales materiales de la ideología. Althusser aclara que la interpelación, el reconocimiento y la asignación suceden siempre-ya, en tanto no existe individuo que no sea-ya sujeto; es decir, que no sea acogido antes del nacimiento en una serie de rituales de un AIE que lo subjetivan (desde el apellido hasta la sexualidad) y sin los cuales el individuo no podría existir en una cultura. La interpelación de los AIE funciona bajo los polos Sujeto-sujeto en una doble relación especular. Por un lado, el Sujeto (la ideología, es decir, el Absoluto sin fallas que se materializa en los rituales como el de obedecer "yo" al maestro) interpela a los individuos como sujetos libres (responsables de la obediencia a las "normas" de la ideología); y por el otro, el sujeto (libre o autónomo) acepta su sujeción al Sujeto cumpliendo solo ("responsablemente") esta sujeción; es decir, la inscripción de su conducta en el lugar asignado: el puesto en la división socio-técnica del trabajo que garantiza la reproducción de las relaciones de producción. Este doble reconocimiento significa que el sujeto no sólo se somete a la ideología, sino que lo hace identificándose con ella: sujeto libre, y por ello, sujetado. Un sometimiento de este tipo no es sino, para Althusser, la forma abstracta que adquiere en la sociedad capitalista la lucha de clases que se libra en los AIE pero que siempre los desborda.

Tras este repaso breve y esquemático por algunos tópicos de la teoría althusseriana es momento ahora de explicitar lo que, consideramos, son sus dos aportes teóricas esenciales para una analítica de la problemática de la propiedad en el modo de producción capitalista. Por un lado, la posibilidad de inteligir el funcionamiento del modo de producción capitalista bajo dinámicas múltiples, no binarias, no lineales, no monocausales, ni mecánicas, sino sobredeterminadas, más sin renunciar por ello a la materialidad de las relaciones de producción y a la "causalidad estructural" de la relación antagónica capitaltrabajo. Por el otro, su teoría ofrece una perspectiva material y positiva de la ideología a partir de su funcionamiento en los rituales de los AIE como productores de sujetos; y ello, 
sin omitir las múltiples combinaciones de los AIE con el Aparato (represivo) de Estado y con los procesos de producción y de circulación donde las relaciones ideológicas "están inmediatamente presentes" produciendo individuos como sujetos, en una lucha de clases que se libra en todo el cuerpo social. En este trabajo sostenemos que ambos aspectos son esenciales para cualquier abordaje de la problemática de la propiedad. Y esto, por dos razones.

La primera de ellas, porque el concepto de sobredeterminación permite eludir el obstáculo de un reduccionismo binario que entendería a la propiedad únicamente como una relación económica, o una relación jurídica sin más. La propiedad no puede ser pensada solamente como el efecto jurídico-ideológico de las relaciones de apropiación y de propiedad "reales"; ya que si bien no hay dudas de que las relaciones jurídico-ideológicas enmascaran, refuerzan y vehiculizan un acto de apropiación basado en la explotación, el fenómeno de la propiedad desborda tales dimensiones descriptivas. El mismo Marx lo subraya en el pasaje de Miseria de la filosofía antes citado: "definir la propiedad burguesa no es otra cosa que exponer todas las relaciones sociales de la producción burguesa". Esto significa que la propiedad es el efecto de un entramado de relaciones sociales, que se expresa en las múltiples instancias de una totalidad social abierta: no sólo en las relaciones de apropiación y de producción, o en el Aparato (represivo) de Estado que sirve de custodio, sino también en la ideología que funciona en el sistema de los AIE y en los sujetos que los aparatos producen.

La segunda razón por la que es importante retomar el análisis de Althusser para un abordaje de la problemática de la propiedad estriba en el carácter productivo de la ideología de la propiedad. En la enumeración que Althusser hace de los AIE aclara que el "Derecho pertenece a la vez al aparato (represivo) del Estado y al sistema de los AIE" (1988: 25). Esto quiere decir que el Derecho puede ser pensado como parte de un orden represivo unificado en el aparato de Estado [de aquí en adelante AE], así como también como parte de la interpelación de los AIE. De ello se sigue que el Derecho no sólo indica una relación de 
prohibición respaldada en el uso masivo de la violencia; sino también una relación de producción mediante el uso masivo de la interpelación ideológica. En otras palabras, la forma jurídica de la propiedad no sólo describe un orden superestructural que enmascara las relaciones de explotación; además, funciona produciendo sujetos sujetados al derecho de propiedad. Éste es quizá el aporte más significativo de la teoría althusseriana a la problemática de la propiedad. La propiedad, no sólo expresa una relación social, económica y jurídica, sino también una relación ideológica en sentido material: la propiedad capitalista se reproduce produciendo sujetos que son interpelados "en gran parte" por los AIE como propietarios. Es decir: produce sujetos que mantienen una relación exclusiva y excluyente con las "cosas" (y "en última instancia" con su fuerza de trabajo y con su medio de producción). Así, los rituales que producen sujetos propietarios pueden ir desde el acto vital de intercambiar trabajo como mercancía, al pedido de permiso de un niño para usar el lápiz de su compañero en clase. Como aclara Althusser esta puesta en marcha de los sujetos no se hace sola, y es objeto de una ininterrumpida lucha de clases al interior y al exterior de los AIE donde las ideologías se enfrentan (1988: 66).

Pues bien, si seguimos la cuestión de fondo planteada por Althusser en "Ideología y aparatos...", y que es, el problema de la reproducción de las condiciones materiales de existencia, cabría entender entonces por "modo de producción capitalista" aquello que los dos primeros términos expresan in stricto sensu: un modo de producir en general. ${ }^{8}$ Esto abarcaría, en la modalidad capitalista, tanto a la producción y reproducción de plusvalía como, fundamentalmente, a la producción y reproducción de las relaciones de explotación.

\footnotetext{
${ }^{8}$ Se trataría del modo de producción entendido como una totalidad, al decir de Jameson (1996), con fuerzas y contrafuerzas, pero en el que cabe destacar su forma productiva: la potencia que es condición para la producción, incluso, de la negación. En este aspecto el modo de producción en sentido amplio, tal y como lo entendemos aquí, se acercaría mucho a la noción de diagrama, que Gilles Deleuze (1987) resalta en Foucault, como un entramado de relaciones sociales de saber-poder inmanentes. No obstante, este concepto teórico debe ser definido históricamente, y allí es donde el tercer término se desplaza al centro. Pues, gracias a su cualificación histórica se revela el tipo de relación predominante que anuda y tensa las demás líneas de fuerza de un diagrama. Tal es lo que sucede con el modo de producción capitalista, donde la relación capital-trabajo asalariado deviene la relación predominante que condiciona al resto de las producciones sociales de ese modo de producción.
} 
Lo que no se garantiza únicamente produciendo al Aparato (represivo) de Estado, sino también a los AIE y a los sujetos que reproducen estas relaciones. En tal sentido, el análisis de Althusser permite desustancializar el derecho de propiedad, entendiendo a las relaciones de propiedad como efectos y vectores que articulan diferentes instancias del cuerpo social produciendo sujetos. Esta producción de sujetos (interpelación) articulada con las relaciones de propiedad y de apropiación, permite comprender el proceso de subjetivación fetichizante de la propiedad bajo el capitalismo neoliberal, no sólo como un efecto secundario de la relación capital-trabajo asalariado, sino también como parte integrante de la dinámica (re)productiva de ese modo de producción. Y en este punto, es evidente la importancia de los AIE.

No obstante, a pesar del potencial teórico de los AIE, esos aparatos carecen de un tratamiento más específico por parte de Althusser. La tarea de ampliar los alcances teóricos de esta noción es asumida, en cierta medida, por Michel Foucault, quien utiliza un concepto muy cercano al de aparato, el de dispositivo. Este concepto nos permite pensar a la propiedad un poco más allá de las relaciones de producción, del AE y de los AIE. De alguna manera, el concepto foucaulteano de dispositivo permite integrar todo esos elementos en el funcionamiento específico (táctico-técnico) de un mecanismo de gobierno que responde a la estrategia global de producción de un sujeto (el propietario). A ese mecanismo específico, que a nuestro juicio opera en la totalidad de un modo de producción capitalista, lo denominaremos dispositivo propietario. Para analizar sus características, es preciso repasar sucintamente la noción de dispositivo en Foucault en relación con el concepto de AIE. 


\section{La táctica de Foucault: de los aparatos al dispositivo}

El vínculo entre los conceptos de AIE y de dispositivo puede ser analizado como un aspecto de la relación difusa que une al pensamiento de Foucault con el de Althusser. ${ }^{9}$ Así, si por un lado, el concepto de dispositivo encuentra cierta filiación con el concepto de AIE aportado por Althusser, como ya lo veremos; por el otro, el concepto de dispositivo señala en Foucault un marcado criterio de diferenciación respecto de las nociones precedentes. Para entender cómo el concepto de dispositivo se vincula al de AIE y adquiere luego su especificidad propia, es preciso exponer, en primer lugar, los aspectos generales comunes a ambos conceptos para, posteriormente, avanzar en su diferenciación mediante algunos criterios aportados por el propio Foucault.

Comenzando entonces por las similitudes. La principal refiere a la estrategia teórica que, de alguna manera, ambos conceptos comparten. Las nociones de AIE y de dispositivo son el resultado de un trabajo analítico astuto que se propone desustancializar las relaciones ideológicas (o de saber) y de dominación (o de poder) tal y como éstas venían siendo planteadas por el marxismo ortodoxo. Así, AIE y dispositivo aparecen con el objetivo de hacer inteligible unas relaciones sociales cuyo funcionamiento escapaba a la visión descriptiva de la tópica base-superestructura para, en el caso de Althusser, "superarla", y en el de Foucault, abandonarla. En este sentido, tanto los AIE como los dispositivos se diferencian del Aparato (represivo) de Estado y del orden jurídico-ideológico superestructural, al contrastar lo abstracto y global de ese orden jurídico con las prácticas materiales al interior de los AIE, o con las tácticas-técnicas inmanentes a los dispositivos. Asimismo, mientras en la visión marxista ortodoxa (Plejanov y Kautsky) el orden jurídicoideológico se caracterizaba por el ejercicio negativo de la violencia y de la ideología como falsa conciencia; el funcionamiento de los AIE y de los dispositivos permitía mostrar el carácter productivo y material de la ideología (a través de la interpelación ideológica de los

\footnotetext{
${ }_{9}^{9}$ Algunos de los trabajos que abordan la relación entre Foucault, Althusser y el althusserianismo son los de Guillaume Le Blanc, Warren Montag y Bob Jessop, reunidos en Lemke (2006).
} 
AIE) o del saber (como reverso del poder productivo de los dispositivos) para la producción de sujetos. Punto éste, en el que tanto AIE como dispositivo coinciden en lo que refiere a su función inmediata: la producción de sujetos sujetados.

Ahora bien, hasta aquí se mencionaron algunas similitudes generales entre ambos conceptos apelando a la deducción de estrategias y funcionamientos comunes, más ello sin salir aun de la teoría althusseriana. En efecto, afirmar que el dispositivo foucaulteano comparte la estrategia analítica de los AIE, y que su funcionamiento recusa la visión "descriptiva" de la tópica estructura-superestructura, al proponerse mostrar el carácter productivo de las relaciones ideológicas (de saber) y de dominación (de poder) a lo largo del cuerpo social, es decir mucho de los AIE y nada del dispositivo. Si bien la noción de dispositivo guarda una relación estrecha con la de los AIE, ella encuentra su especificación en una estrategia que enfrenta a Foucault, no sólo con el marxismo ortodoxo, sino también con el marxismo de Althusser. Aun, cuando este enfrentamiento pueda ser visto, en alguna medida, como una operación retórica deshonesta: la que arroja a Althusser al marxismo ortodoxo, con el aparato de Estado y el "modo de producción", para quedarse luego con aquello que el pensador de los AIE dejó sin desarrollar (el funcionamiento de estos aparatos). Sin embargo, más allá de la estricta filiación entre el concepto de dispositivo y el de AIE, lo cierto es que el concepto de Foucault abarca una dimensión analítica mayor a la que revisten los aparatos de la teoría althusseriana. Mayor, por un lado, porque los dispositivos describen a nivel "microfísico" lo que ocurre en, entre y debajo de los AIE. Mayor, por otro, porque los dispositivos anudan relaciones de saber y de poder que no pueden ser remitidas a un principio general y coherente de dominación de clase en la forma del Aparato (represivo) de Estado, sino que estos dispositivos forman circuitos inmanentes cuya especificidad táctico-técnica no se deduce de las relaciones de producción, sino de las múltiples estrategias globales a las que responden en una situación histórica dada.

Foucault hace explícitas las diferencias entre aparato y dispositivo en su curso de 1975-6 Defender la sociedad. En la clase del 7 de enero expone su punto de vista sobre el abordaje de la problemática del poder por medio de una crítica doble, que involucra a la 
concepción liberal del poder y a la concepción marxista. La particularidad que tiene esta crítica es que, mientras de un lado recusa la concepción jurídica del poder, retomando argumentos de la crítica de Marx, del otro, emparenta a la "concepción marxista" con la concepción jurídica, bajo la posición que denomina del "economicismo en la teoría del poder". Según la primera concepción, el poder "es considerado como un derecho que uno posee como un bien y que, por consiguiente, puede transferir o enajenar, de una manera total o parcial, mediante un acto jurídico o un acto fundador de derecho - por el momento no importa- que sería del orden de la cesión o el contrato [...] En esta serie, en este conjunto teórico al que me refiero, la constitución del poder político se hace, entonces, según el modelo de una operación jurídica que sería del orden del intercambio contractual" (2008a: 27). En la concepción marxista, "tenemos algo distinto, que podríamos llamar funcionalidad económica del poder [...] en la medida en que el papel del poder consistiría, en esencia, en mantener relaciones de producción y, a la vez, prorrogar una dominación de clase que el desarrollo y las modalidades características de la apropiación de las fuerzas productivas hicieron posible" (ibíd.). Sin embargo, lo común a ambas perspectivas es que el poder tiene una relación secundaria respecto de las relaciones económicas (contractuales o de producción). Frente a ello la apuesta metodológica de Foucault "consiste en determinar cuáles son, en sus mecanismos, sus efectos, sus relaciones, esos diferentes dispositivos de poder que se ejercen, en niveles diferentes de la sociedad, en ámbitos y con extensiones tan variadas" (ibíd.: 26). El enfoque, por consiguiente, no estará puesto en las relaciones económicas o en el derecho como su producto, sino antes bien en los dispositivos como mecanismos de poder cuyo funcionamiento específico no puede ser deducible, para Foucault, de unidad previa alguna.

Esta crítica de Foucault no se dirige sólo a confrontar los dispositivos con el "economicismo" liberal o marxista, y en términos generales, con la tópica descriptiva basesuperestructura; avanza más allá, desmarcándose de aquella teoría que se propuso, precisamente, "superar" este binarismo a través del concepto de AIE: la teoría althusseriana. En clara alusión a ella, Foucault dice: 
"No pretendo decir, desde luego, que no hay grandes aparatos de poder o que no se pueden alcanzar ni describir. Creo, empero, que siguen funcionando sobre la base de esos dispositivos de dominación. Concretamente, es posible, por supuesto, describir el aparato escolar o el conjunto de los aparatos de aprendizaje en una sociedad dada, pero creo que sólo es posible analizarlos eficazmente si no se los toma como una unidad global, si no se trata de deducirlos directamente de algo que sería la unidad estatal de soberanía y, en cambio, se intenta ver cómo actúan, cómo se apoyan, de qué manera ese aparato define cierta cantidad de estrategias globales, a partir de una multiplicidad de sometimientos (el del niño al adulto, el de la prole a los padres, el del ignorante al culto, el del aprendiz al maestro, el de la familia a la administración, etcétera). Todos esos mecanismos y operadores son el basamento efectivo del aparato global que constituye el aparato escolar. Por lo tanto, si así lo quieren, considerar las estructuras de poder como estrategias globales que atraviesan y utilizan tácticas locales de dominación" (2008a: 50. Cursiva propia).

Como se deduce de esta crítica de Foucault a la concepción althusseriana del Estado y los AIE, los dispositivos se distinguen de los aparatos en términos de su antecedencia (¿teórico-metodológica?), de su eficacia técnica, de su localización inmanente y de sus estrategias múltiples. Los dispositivos en tanto "mecanismos y operadores son el basamento efectivo del aparato global que constituye el aparato escolar"; de aquí que su funcionamiento no pueda ser deducido ni subordinado al funcionamiento de una unidad global previa tales como el Estado y las relaciones de producción. ${ }^{10}$

En 1977 Foucault ofrece una entrevista en la que se explaya sobre las características del dispositivo. Afirma que el dispositivo es la red que puede establecerse entre elementos "decididamente heterogéneo que comprende discursos, instituciones, arquitectura, reglamentos, leyes, medidas administrativas, enunciados científicos, proposiciones

\footnotetext{
10 Más adelante, Foucault insiste en esta diferencia de perspectiva con el marxismo en general y con el althusseriano en particular: “¿La relación de poder es en el fondo una relación de enfrentamiento, de lucha a muerte, de guerra? Por debajo de la paz, el orden, la riqueza, la autoridad, por debajo del orden apacible de las subordinaciones, por debajo del Estado, de los aparatos del Estado, de las leyes, etcétera, ¿hay que escuchar y redescubrir una especie de guerra primitiva y permanente? Ésa es la cuestión que querría plantear desde el inicio, sin desconocer todas las demás cuestiones que sin duda habrá [que plantear] y que trataré de abordar en los próximos años, y entre las cuales se pueden citar simplemente, a título de primera referencia, las siguientes: ¿la existencia de la guerra puede y debe considerarse efectivamente como primera con respecto a otras relaciones (las de desigualdad, las disimetrías, las divisiones del trabajo, las relaciones de explotación, etcétera)? ¿Los fenómenos de antagonismo, rivalidad, enfrentamiento entre individuos, grupos o clases pueden y deben reagruparse en ese mecanismo general, en esa forma general que es la guerra?" (2008a: 52). Sobre este punto en particular, véase Deleuze (1987: 52-57).
} 
filosóficas, morales, filantrópicas [...] lo dicho y lo no-dicho" (1984: 128). Y que, en tanto red, el dispositivo, "establece la naturaleza del vínculo que puede existir entre estos elementos heterogéneos" (ibíd.), haciéndolo funcionar bajo una estrategia determinada. Respecto de la génesis del dispositivo, indica que se "trata de una formación que en un momento dado ha tenido por función responder a una urgencia. El dispositivo tiene así una función estratégica dominante. Esta pudo ser, por ejemplo, la reabsorción de una masa de población flotante que a una sociedad con una economía esencialmente de tipo mercantilista le resultaba embarazosa" (ibíd.: 129). El dispositivo, entonces, emerge ante una urgencia: responde a una estrategia dominante hasta alcanzar su generalización. Tercero, y en relación a su funcionamiento, Foucault señala que el dispositivo se constituye y permanece como tal, en la medida en que es el lugar de un doble proceso: "proceso de sobredeterminación funcional, puesto que cada efecto, positivo o negativo, querido o noquerido, llega a entrar en resonancia, o en contradicción, con los otros, y requiere una revisión, un reajuste [...]. Proceso, por otra parte, de perpetuo relleno estratégico" (ibíd.). Ha de advertirse aquí que la "sobredeterminación" del dispositivo reviste casi iguales características que la sobredeterminación althusseriana: las contradicciones específicas al funcionamiento de este mecanismo. No obstante, Foucault suma otro rasgo: el relleno estratégico. Esto es, la aparición de efectos inesperados que producen siempre una reorientación de la estrategia inicial a la que el dispositivo debía responder. Por último, el dispositivo tiene por efecto dominante la producción de sujetos. Así, el dispositivo carcelario produce delincuentes y el dispositivo sexual individuos y poblaciones sanas. Esta última particularidad del dispositivo lo asimila, como sugerimos, a la función de los AIE. Y éste es el punto en el que el análisis de Foucault se empalma con el de Althusser para, allí mismo, alejarse de él.

En efecto, mientras la teoría althusseriana iluminaba un aspecto de la función ideológica del modo de producción capitalista: la producción de sujetos a través de los AIE; el análisis de Foucault prolonga esta perspectiva, pero desunificándola o descentrándola de los aparatos, y ampliándola a los niveles microfísicos de las relaciones de saber-poder. No 
obstante, también reconoce que estas relaciones desigualitarias que se estabilizan implican, en algún punto, una centralización y un ejercicio de arriba abajo que es efecto de las microrelaciones de saber-poder (1984: 134). Con todo, los dispositivos se presentan para Foucault como los mecanismos y operadores táctico-técnicos, que responden a estrategias múltiples, sobredeterminadas y rellenas, organizando las relaciones de fuerza, su desigualdad y estabilización, a través de la producción y destrucción de los cuerpos individuales y colectivos. Estos operadores actúan a nivel local y sobre los cuerpos, a través de múltiples técnicas que configuran prácticas, generando formas del ver y del hablar. Quizá estemos muy cerca aquí del concepto de ideología en Althusser (como rituales de la vida cotidiana); sólo que en este último faltaba una analítica de esos mecanismos desde el punto de vista microfísico por el que esos rituales materiales se producían y conservaban, algo que el "nominalismo" de Foucault supo identificar y describir con genial maestría. ${ }^{11}$

\section{El dispositivo propietario}

Como vemos el concepto de dispositivo en Foucault comprende una red de elementos heterogéneos que actúan a nivel inmanente. El dispositivo enlaza de manera transversal relaciones de saber-poder generando las condiciones para la producción de un sujeto histórico específico. Entendemos por tanto que el dispositivo reúne y estabiliza elementos generales, tales como relaciones de producción, aparato de Estado, aparatos ideológicos y discursos, entre otros, a través de una red microfísica de saber-poder que modela los cuerpos estableciendo un modo de relación (prácticas) entre unos y otros. Así, el cuerpo-trabajador, el cuerpo-capitalista, el cuerpo-funcionario, el cuerpo-gobernante, el cuerpo-militar, el cuerpo-maestro, el cuerpo-médico, el cuerpo-delincuente, etc. se relacionan según la función específica para la que fueron producidos a la vez que se condicionan de forma mutuamente (por ejemplo, en la relación cuerpo-maestro y cuerpo-

\footnotetext{
${ }^{11}$ En La voluntad de saber (1976), Foucault propone adoptar el punto de vista nominalista para el análisis del poder, ofreciendo una de las pocas definiciones concisas del mismo: "Hay que ser nominalista, sin duda: el poder no es una institución, y no es una estructura, no es cierta potencia de la que algunos estarían dotados: es el nombre que se presta a una situación estratégica compleja en una sociedad dada" (Foucault, 2009: 89).
} 
alumno). En este sentido, podemos afirmar que el sujeto propietario es un cuerpopropietario, producido en una red de relaciones de saber-poder que funciona a escala macrosocial y microsocial. En efecto, en la producción de un cuerpo-propietario intervienen, desde relaciones macrosociales, como la de capital-trabajo, a relaciones microsociales como la de cuerpo-operario y cuerpo-vigilante; desde la relación ciudadanoEstado a la relación cuerpo-ciudadano y cuerpo-funcionario; o desde el vínculo delito-pena al vínculo cuerpo-delincuente y cuerpo-policial, junto a una multiplicidad de relaciones espesa y entrecruzadas.

Como afirmábamos antes, la construcción de un cuerpo-propietario debe entenderse como el efecto de relaciones de saber-poder inmanentes en la que elementos heterogéneos son anudados para producir estratégicamente una subjetividad propietaria. Estos elementos pueden ir desde la organización del trabajo en las viejas casas taller o workhouses (con sus técnicas morales de vigilancia y de castigo), a la arquitectura de los hogares (con la habitación matrimonial como espacio íntimo); desde la legislación contra pobres (apoyada en la violencia de la espada) a los reglamentos escolares (que formaban al buen ciudadano); y desde el discurso de un diario íntimo (con el registro autobiográfico) a los tratados filosóficos-jurídicos (con el derecho subjetivo como huella), entre otros. El sujeto propietario es el producto de un dispositivo propietario; es decir, de mecanismo que define la naturaleza del vínculo entre todos estos elementos en función de una estrategia global motivada por una urgencia histórica, a la que inmediatamente referiremos.

A propósito de esto, vale decir que Marx tenía plena consciencia del papel que cumplían ciertos mecanismos no económicos en el proceso de subsunción del trabajo al capital. Así lo deja en claro en el célebre capítulo XXIV de El capital:

"No basta con que las condiciones de trabajo se presenten en un polo como capital y en el otro como hombres que no tienen nada que vender, salvo su fuerza de trabajo. Tampoco basta con obligarlos a que se vendan voluntariamente. En el transcurso de la producción capitalista se desarrolla una clase trabajadora que, por educación, tradición y hábito, reconoce las exigencias de ese modo de producción como leyes naturales, evidentes por sí mismas" (Marx, 2004: 922). 
Para Marx, la subsunción del trabajo al capital no se explica únicamente por la separación de los productores de sus medios de producción. Tampoco por el uso de la violencia que obliga al trabajador a venderse. Es necesario, además, que el trabajador sea producido como tal mediante la educación, la tradición y el hábito. En otras palabras, se necesita la utilización de unos mecanismos que actúen conjuntamente con las relaciones de producción y el aparato (represivo) de Estado para producir un sujeto que se conduzca como trabajador asalariado. Estos mecanismos u operadores tácticos-técnicos son, a nuestro entender, los dispositivos. Y de hecho, Foucault explora la emergencia de alguno de estos dispositivos (los disciplinarios, el médico-legal, el carcelario, la sexualidad, los de seguridad, el familiar, entre otros) en el período de emergencia y crecimiento del aparato productivo capitalista, así como de incremento de una población flotante peligrosa (la de trabajadores "libres") a la que era urgente insertar al medio de producción garantizando su utilidad económica y su docilidad política (Foucault, 2008b: 251-255).

De manera que es posible pensar a la propiedad, no sólo como un acto de apropiación de una relación social de producción, o como la expresión jurídico-ideológica del aparato de Estado; sino y más generalmente, como un mecanismo de gobierno o dispositivo que reúne estos elementos y otros, y que tienen por efecto estratégico la producción de un sujeto propietario. Dispositivo que emerge ante una urgencia: la de organizar las multiplicidades humanas en el periodo de acumulación capitalista. Que responde a una estrategia dominante: la subsunción de una población a la ley del Estado y al aparato productivo naciente. $Y$ que se generaliza para producir un sujeto propietario universal: el individuo dueño de su fuerza de trabajo (la clase trabajadora) y el individuo dueño de los medios de producción por justo título (la clase capitalista).

Ahora bien, retomando los elementos analíticos hasta aquí expuestos es momento de ofrecer un balance provisorio en relación al estatuto actual de la propiedad.

Ante la visión metafísico-culturalista de la propiedad promovida por los discursos neoliberales se impone una perspectiva analítica que contemple, por un lado, el carácter 
ideológico de la mistificación del derecho de propiedad que, bajo la acción del "tener", encubre y vehiculiza el acto de apropiación y las relaciones de propiedad fundadas en la relación de explotación. Esto quiere decir, que un análisis de la propiedad debe priorizar el momento de la totalidad (con sus tensiones, denegaciones y densos entramados). O para decirlo de otra forma: situar al particular-propiedad en el modo de producción (en este caso, el capitalista-neoliberal). Lo que significa invertir el punto de vista de la perspectiva neoliberal que convierte al particular en el universal, tomando la parte por el todo; figura ideológica por antonomasia. Por otro, y frente a la naturalización de la propiedad como un componente esencial al individuo-humano, es imperioso un análisis que avance más allá de la forma negativa de la ideología jurídica, liberal y neoliberal, para contemplar su carácter productivo (como interpelación) a través de la acción de los aparatos de Estado, pero más específicamente a través de la acción del dispositivo propietario. ${ }^{12}$ La producción de un sujeto propietario se extiende más allá del orden jurídico, de hecho enreda a ese orden jurídico en prácticas sociales heterogéneas, donde lo jurídico cobra renovada fuerza, a la vez que las resistencias se suscitan. Piénsese, por ejemplo, en la necesidad cada vez mayor de regular la propiedad intelectual (que en la actualidad tanto preocupa a organismos como la OMC) ante la valorización creciente de los bienes intangibles y los problemas en torno a la piratería, adoptando para ello protocolos de seguridad mucho más sofisticados. Estas técnicas, no sólo amplían los efectos de vigilancia sobre la población, sino que además producen una fragmentación posesiva de la realidad donde las formas de exclusión para el intercambio se multiplican generando nuevas formas de apropiación del cuerpo (ideas, información genética, imagen, etc.). Y, en paralelo con esta multiplicación de técnicas de privatización, se asiste a una superposición creciente de lo íntimo (privado) sobre lo público, cual correlato de una apropiación individual ilimitada.

12 En la actualidad, estos mecanismos e instituciones no pueden limitarse al dominio estatal, pues el dispositivo propietario se extiende hoy a niveles supraestatales encadenándose a múltiples organismos, entre ellos, el Banco Mundial y la Organización Mundial del Comercio. Sobre la interpelación ideológica de los organismos internacionales remitimos a Susana Murillo (2008). 
Como vemos, la problemática de la propiedad no puede ser pensada hoy por fuera de la totalidad del modo de producción capitalista neoliberal, ni omitiendo las prácticas particulares en las que se evidencia, en términos efectivos, la producción de sujetos. A nuestro entender el dispositivo propietario, como operador táctico-técnico, permite inteligir esas prácticas heterogéneas del orden microfísico en términos estratégicos, articulándolas con la totalidad del modo de producción. Para decirlo en términos dialécticos, y a riesgo de simplificaciones, el dispositivo propietario, como concepto teórico, permite inteligir las prácticas particulares de apropiación, articulándolas con el modo de producción universal (hegemónico), mostrando así cómo se singulariza (cualifica) un cuerpo en la forma de un ser propietario.

No obstante, esta mirada acerca del dispositivo abre varios interrogantes: ¿qué papel ocupa en este proceso de cualificación de los cuerpos el sujeto sujetado? ¿Es sólo un efecto de mecanismos microfísicos en un orden macrosocial? Y si estos mecanismos actúan a nivel "externo" ¿por qué el sujeto no advierte su forma opresiva en términos objetivos? Y lo que es más importante para nosotros: ¿por qué los individuos se identifican con la condición de propietarios individuales sin experimentar ninguna contradicción entre, por ejemplo, el estatuto del propietario trabajador y el estatuto del propietario capitalista?

En el apartado siguiente intentaremos dar algunas respuestas a estas preguntas a partir de la descripción de un aspecto poco atendido del dispositivo, su condición de soporte anímico.

\section{El dispositivo propietario como soporte anímico}

Hasta aquí se argumentó que el sujeto propietario es el efecto de un entramado de relaciones de saber-poder anudadas estratégicamente por el dispositivo propietario, dispositivo al que situamos históricamente en el modo de producción capitalista. Ahora bien, afirmar que el sujeto propietario es un efecto de relaciones de saber-poder articuladas por un dispositivo, no agota allí el problema de la sujeción del sujeto al régimen de la 
propiedad privada. Pues, este vínculo no puede verse únicamente en la dirección de un sometimiento más o menos forzada del sujeto al dispositivo, porque también existe allí un acto de identificación por parte de ese sujeto con la condición de propietario que el dispositivo configura. Para decirlo sin rodeos: en la producción de un sujeto propietario interviene un acto de reconocimiento (como advirtiera Althusser al referir a la interpelación) por el cual el sujeto adhiere a esa sujeción, o se implica en ese mecanismo que lo produce como sujeto (Butler, 2001). De modo que la sujeción no resulta sólo de la asignación impuesta de un lugar más o menos variable en el orden social en el que se nace, sino también y simultáneamente de la acción voluntaria (consciente e inconsciente) de ese sujeto con miras a ocupar una posición en ese entramado, modificando o no el estado presente de las relaciones de fuerza. En otras palabras, la sujeción guarda siempre un componente anímico, por el cual el sujeto se reconoce como siendo eso y no otra cosa, y produciéndose como sujeto en una relación de sujeción.

Pues bien, para referir a esta dimensión del dispositivo, proponemos utilizar el término "anímico", en alusión al alma o psique, pero sin reducir esta noción a su encuadre disciplinario o psicológico. Por anímico entendemos la conciencia corporal, afectiva, práctica y simbólica. Esta conciencia no refiere a un estado reflexivo o autoconsciente, sino a un modo de existencia en el que la constitución corporal, afectiva, práctica y simbólica adquieren una singularidad sobre el fondo de lo no consciente. Es decir, sobre el hecho de ser-ya una materialidad "biológica", un cuerpo que lucha contra la muerte, atravesado por dolores y placeres; un ser apasionado y con capacidad para simbolizar y actuar en un orden social en el que se nace, y que también se asienta sobre un terreno fangoso (el de la potencia y el devenir). ${ }^{13}$

\footnotetext{
${ }^{13}$ Sobre la adhesión afectiva del sujeto a la ley desde un punto de vista psíquico y su co-implicancia con las formas "externas" de dominación remitimos a Butler (2001).
} 
En este sentido, consideramos que la problemática de la propiedad no puede reducirse a las relaciones de apropiación y de propiedad, aun cuando encuentren en ella su principal anclaje (la apropiación para la producción y reproducción de las condiciones materiales de existencia); o a la fuerza represiva del Estado, aun cuando esta obligue a respetar la ley a riesgo de muerte. La problemática de la propiedad comprende al conjunto de relaciones de saber-poder que un dispositivo propietario organiza. Este dispositivo involucra en su funcionamiento una dimensión anímica: produce una modalidad de existencia a la que el sujeto se somete (o no) para salvarse en tanto ser corporal, afectivo, práctico y simbólico. Así en todo acto de apropiación hay adhesión o implicación en tanto el sujeto constituido se constituye a la vez como ser a preservar por medio de ese acto. Este ser a preservar no es el efecto terminal de las relaciones de saber-poder, como sujeto que reproduce mecánicamente acciones para la estabilización y conservación de las asimetrías; es un sujeto producido que al mismo tiempo se autoposiciona en relación con principios ontológicos a los que abraza y con los que se identifica, que lo apuntalan, y que ponen en juego su existencia. Tales principios, por cierto, no emergen de lo anímico, sino de un entramado de saber-poder; sucede que es el sujeto quien experimenta anímicamente esta implicación o rechazo. Así si el trabajador asalariado ofrece su fuerza de trabajo como propiedad, ello es a causa tanto de la red de imposiciones económicas, disciplinarias, ideológico-jurídicas y militares que hacen del trabajo un principio casi irrenunciable, como de la experiencia anímica por la cual el sujeto se identifica (o no) con el trabajo como principio garante de su existencia corporal, afectiva, práctica y simbólica (el trabajo como un valor transmitido desde la cuna y por el que obtengo el reconocimiento de mis padres y de otros).

De lo dicho hasta aquí se sigue que el dispositivo propietario se presenta para el sujeto como un soporte de su existencia, un soporte anímico. Este aspecto anímico del dispositivo conforma lo "subjetivo-estructural" de la relación entre sujeto (lo anímico) y propiedad (el dispositivo-soporte). 
Cuando decimos que el dispositivo conforma lo "subjetivo-estructural", queremos indicar con ello que el dispositivo es mucho más que un orden ideológico que se impone de manera irremediable al sujeto. Sin duda, el dispositivo es ideológico y se produce (y reproduce) en el modo de producción en el que dicho dispositivo funciona. Pero el dispositivo como soporte no actúa únicamente imponiendo desde el "exterior" un orden ideológico al sujeto, el soporte no es el tablero en el que el sujeto se posiciona, sino que es el marco de referencia que él también construye (o modifica) y adopta (o rechaza) como resultado de la experiencia ideológica a nivel anímico. En términos más esquemáticos podemos decir que, si a primera vista el dispositivo propietario parece funcionar desde la organización ideológica del modo de producción social al sujeto; el dispositivo como soporte anímico se conduciría en la dirección inversa: de la capacidad anímica del sujeto al soporte, es decir, al marco de referencia o modelo de acción que me integra (o no) al dispositivo y, con él, al modo de producción social. El soporte sería el principio que el sujeto reconoce (en términos ideológicos) como fundamental para su existencia aun cuando esto implique ya la sujeción al dispositivo. En rigor, soporte y dispositivo, son indistinguibles prácticamente, y esta división sólo funciona a modo virtual. No obstante, su distinción permite reconocer la dimensión subjetiva que garantiza el éxito de la sujeción al dispositivo propietario en tanto soporte del sujeto; así como también advertir sobre posibles inflexiones, cortocircuitos, inversiones, disputas, resistencias y derivas a nivel macrosocial y microsocial como consecuencia del rechazo y/o modificación de un soporte anímico determinado. Sostenemos entonces que el dispositivo propietario no puede ser reducido a un mecanismo al que los individuos se someten ineluctablemente de forma pasiva; el dispositivo propietario se presenta también como un soporte de la existencia corporal, afectiva, práctica y simbólica del sujeto. En suma: el dispositivo, en su dimensión anímica, permite inteligir las prácticas de involucramiento (o rechazo) de los sujetos con un operador táctico-técnico que se presenta ideológicamente como un soporte (o también como una forma insoportable) para el sujeto. 
Para ofrecer algunas evidencias respecto a la condición de soporte anímico del dispositivo propietario, es importante revisitar algunos discursos filosóficos de la modernidad.

\section{El sujeto propietario y su soporte}

Sin duda, debemos a Hegel el mérito de haber señalado la importancia de esta dimensión anímica en la subsunción del sujeto al derecho de propiedad, cuando en Principios de la filosofía del derecho (1821) explicó el acto de apropiación en los términos de una transformación de la subjetividad de la personalidad (encerrada en la niñez-animal) a la objetivación en las cosas a través de la apropiación (Hegel, 1999: 125 y ss.). Allí, Hegel sostiene, que en la imposición de la voluntad libre sobre las cosas el animal-hombre transita de la niñez (que para el derecho romano es igual a ser una propiedad del padre) a la ciudadanía (que lo convierte en un adulto libre). Esta subsunción de la persona al orden jurídico (liberal) conlleva un acto de implicación por parte del sujeto apropiador con el objetivo de garantizar, no sólo su existencia física, sino su constitución como persona. En otras palabras, la propiedad se presenta a Hegel como el medio que integra y subsume a la persona a la comunidad, al permitir el mutuo reconocimiento entre las personas (propietarias) como ciudadanos, luego de realizada su voluntad sobre la cosa: "puesto que por medio de la propiedad le doy existencia a mi voluntad, la propiedad debe tener la determinación de que algo sea mío. Esta es la importante doctrina de la propiedad privada" (1999: 131). Así, para Hegel, el acto de apropiación es mucho más que un acto de subsunción al derecho, es un acto de implicación voluntaria por medio del cual el sujeto se produce como un ser autoconsciente, es decir, como un sujeto subsumido al régimen jurídico de la propiedad en razón de su involucramiento en cuerpo, praxis y espíritu. Y por cierto, los tres momentos de la dialéctica interna de la propiedad que Hegel expone a lo largo del capítulo sobre la propiedad (la toma de posesión, el uso y la enajenación) muestran que el sujeto se somete al derecho en la misma medida en que se produce como persona. 
Esta esfera anímica que el idealismo de Hegel reconoce como parte constitutiva del derecho liberal, alcanzará su forma hiperbólica en uno de sus discípulos: Max Stirner. En su escrito El único y su propiedad (1844), Stirner afirma que "[l]a individualidad, es decir, mi propiedad, es, en cambio, toda mi existencia y esencia, es Yo mismo" (2007: 161). La sentencia de Stirner puede ser analizada, como lo hizo Marx en la Ideología alemana (1845), como la expresión sobreidalizada del derecho burgués que convierte a la propiedad en un mero predicado del Único. En este sentido, la teoría de Stirner sería una muestra singular del modo en el que el derecho burgués se introyecta en la conciencia de los hombres, al imaginarse como individuos autofundados por acción de la palabra "mío". Y, en efecto, Marx entiende al Único stirneriano como un producto singular pero en todo coherente con el modo de producción capitalista y las relaciones de exclusión entre propietarios que el derecho liberal encubre. Con ello, una teoría como la de Stirner que en esencia buscaba enaltecer la existencia empírica del individuo confrontándola con los universales "Estado" o "modo de producción", acaba convirtiéndose en una teoría que hace del individuo un universal de la forma empírica del Estado burgués y del modo de producción capitalista.

No obstante lo implacable de la crítica marxiana, la teoría de la propiedad de Stirner refleja un aspecto ontológico notable de la subjetividad del Único, y que es, que el individuo stirneriano sólo puede conservarse en la medida en que se autoposiciona imaginariamente como propietario. En efecto, a partir de mi relación con los otros en tanto que propietario adquiero conciencia de lo "mío" como "propio"; mi existencia corporal, afectiva, práctica y simbólica se vuelve consciencia "mía", a la vez que las sensaciones de la carne, las afecciones, las acciones y los pensamientos aparecen como expresiones de un centro: el "mío". De esta forma, la propiedad emerge como índice del poder corporal, afectivo, práctico y simbólico del Yo; sin ella peligraría "mí" vida, me desintegraría como individualidad. Es precisamente este vínculo subjetivo-estructural el que está en el corazón del sujeto stirneriano y que atestigua los efectos de la propiedad en tanto soporte anímico. 
Un año antes de escribir la crítica al Único y su propiedad, Marx apunta en los Manuscritos de 1844 que la propiedad privada tiene por misterio el de ser, por un lado, el producto del trabajo enajenado y, por otro, "el medio a través del cual el trabajo se enajena, la realización de esta enajenación" (Marx, 2010: 117-118). Homologada por Marx al pecado original (a un principio sin historia, mancha imborrable de la conciencia humana) la propiedad privada se reconoce como un producto del trabajo enajenado pero también como un principio que hace que el trabajo se enajene. La explicación radica en el hecho de que el trabajo es una propiedad del trabajador cuyo producto le es enajenado. "El trabajador-dice Marx- pone su vida en el objeto; pero aquella ya no le pertenece a él, sino al objeto" (Marx, 2010:107). Ahora bien, ¿qué hace que el trabajador ponga su vida en un objeto que no le pertenece? ¿Por qué el trabajador invierte en su alienación? Si adoptamos el punto de vista ontológico, que Marx propone en el manuscrito, la respuesta la encontraríamos en la incorporación de la propiedad como sostén de la existencia: "en la medida en que la propiedad privada se incorpora al propio hombre, y el hombre mismo es reconocido como un ser [...] el hombre mismo es colocado en la determinación de la propiedad privada [...]" (Marx, 2010: 134). En este punto, la enajenación se presentaría como el momento negativo de la afirmación del trabajo como propio. Pues, para que la vida no le pertenezca más al trabajador, sino al objeto, es necesario que el trabajador ponga su vida en el objeto como suya. Es decir, se requiere que el trabajador se produzca como propietario natural de su trabajo, a partir de colocarse "a la propiedad privada como esencia del ser humano" (Marx, 2010: 134). Así, en la identificación del trabajador con la esencia del ser humano (la propiedad privada) Marx parece haber hallado el fundamento de la enajenación. La propiedad se convierte en el soporte del trabajador gracias a que ella se experimenta anímicamente como esencial al hombre.

Ahora bien, la incorporación de esta esencia de la propiedad (a la que Marx homologa a un principio religioso larvado en la conciencia del hombre: el pecado original), hace pensar que la inversión del trabajador en la propia alienación requiere a la par de la producción de cierta interioridad. Pues sin el repliegue del sujeto sobre su "sí mismo" sería 
imposible para el trabajador ofrecer "voluntariamente" su fuerza de trabajo como algo propio. ${ }^{14} \mathrm{Y}$, para que la propiedad se incorpore al hombre, es necesario producir un efecto de diferenciación entre el interior y el exterior de mi cuerpo; digamos, una cavidad interior donde alojar al alma propietaria, un espacio íntimo y exclusivo, preservado del resto de los hombres y sólo accesible a mí. ${ }^{15}$ En otras palabras, para que la propiedad del trabajo sea parte de mí y objeto de mi voluntad debo pensar al sujeto como un ser con profundidad, alguien separado de los otros por un cuerpo propio cuyo principio de acción se instala al interior de la carne; vale decir, pensar al hombre como un "individuo-en-el-mundo".

La fórmula le corresponde al antropólogo Louis Dumont (1987), quien la utiliza para diferenciar el individualismo religioso (cuya historia podría remontarse a las sectas órficas del siglo VII a.C. hasta entrado el cristianismo) del individuo mundano de la modernidad. Mientras Dumont define al individuo religioso como un "individuo-fuera-del-mundo", por edificar su Yo en relación a un más allá interiorizante; reserva la categoría de "individuo-en-

\footnotetext{
${ }^{14}$ En efecto, Marx piensa aquí la enajenación a partir de Hegel. Para Hegel el acto de enajenación de la propiedad del trabajo implica la voluntad del propietario de convertir en exterior una parte de la totalidad de su fuerza. Tal exteriorización se asienta en la distinción entre la propiedad de la totalidad de su fuerza y la porción de esa propiedad que se exterioriza. Para llegar a esto es necesario que el hombre salga de su inmediatez natural y que mediante su autoconsciencia se aprehenda como libre, que se tome él en posesión y devenga propiedad de sí mismo y frente a los otros. Con esto "se pone al mismo tiempo como lo suyo y como objeto separado de la simple autoconsciencia, tornándose así susceptible de adquirir la forma de la cosa" (Hegel, 1999: 141). Es esta autoconsciencia de la "libertad" del trabajador por la que se capta como propietario de la totalidad de sus fuerzas la que le permite enajenar voluntariamente parte de ella. En esto radica la diferencia fundamental entre el peón o el trabajador asalariado y el esclavo, pues mientras unos son sujetos, el otro es naturaleza inmediata (Hegel, 1999: 154). Vale agregar que estamos en presencia de un modo de producción basado en la explotación del trabajo "libre", por lo que la esclavitud tiende a verse, comprensiblemente, como una anomalía. De aquí, la recusación de Hegel a Kant por considerar al principio de la autopropiedad una antinomia (si soy dueño de mí mismo podría consentir en mi esclavitud). Para Hegel el cuerpo es inseparable del hombre y por tanto es inajenable de su personalidad (1999: 132; 143-145). Hegel es consciente de que esta inalienabilidad del cuerpo sólo es posible históricamente bajo la idea de libertad del Estado burgués, es decir, bajo los principios del derecho liberal que toman al hombre por ciudadano y no por súbdito o esclavo. No obstante, el hecho de que el cuerpo no pueda ser enajenado, atestigua la constitución plena del individuo liberal como un ser separado de los otros por un cuerpo propio.

${ }^{15}$ La intimidad es uno de los elementos que el dispositivo articuló en la producción de un sujeto propietario. $Y$ es que lo íntimo es el índice de una vida privada en la que el hombre se relaciona de manera exclusiva y excluyente con su cuerpo, su espacio y sus cosas. Sobre la construcción de esa vida íntima y privada en la modernidad, remitimos a las evidencias aportadas por Ariès y Duby (1991).
} 
el-mundo" para aquel individuo que encuentra en el aquí del mundo su lugar como un ser separado de los otros y de las cosas. Si bien esta genealogía del individualismo se remonta a tiempos muy anteriores a los de la modernidad capitalista, lo cierto es que la conformación de ese individuo-en-el-mundo encuentra en el capitalismo liberal, y particularmente en la institución de la propiedad privada, un momento de radicalización. A este respecto, no hay dudas de que el aporte de Macpherson (1970) sobre el surgimiento de un "individualismo posesivo" representa un antecedente valioso para la clarificación del vínculo entre la subjetividad propietaria y la sociedad capitalista liberal o "sociedad posesiva de mercado", como la llamó. Ciertamente, su trabajo permitió reconocer una dimensión ontológica constitutiva de la sociedad capitalista, adoptando para ello un punto de vista original sobre el pensamiento político inglés del siglo XVII, y particularmente, sobre las teorías de Hobbes y Locke. No obstante ello, coincidimos con Dumont en que "la posesión no es un accidente histórico pasajero de un fenómeno permanente que se llamaría individualismo; por el contrario, el individualismo levanta cabeza bajo el aspecto de la posesión o de la propiedad, abate todo lo que quedaba de sumisión de hecho y de jerarquía ideal en la sociedad, y se instala él mismo en el trono así vaciado" (Dumont, 1982: 78).

La propiedad no es una cualidad del individuo (liberal), sino que es el elemento por cual el sujeto se produce como individuo-en-el-mundo, por la acción de un dispositivo propietario que funciona al interior del modo de producción capitalista. En este sentido, la propiedad es, al decir de Castel (2010), lo que puede garantizarle al individuo una consistencia cuando no dispone ya de esos puntos de apoyo tradicionales o trascendentes: "[...] el individuo moderno, el ciudadano, es aquel que es indisociablemente propietario de sí mismo, y poseedor de bienes [...] puede ser propietario de sí mismo, no estar bajo la dependencia de otro o de la necesidad, porque puede apoyarse, tener como soporte la propiedad, que es la condición de posibilidad necesaria de esta independencia" (2010: 310. Cursiva propia). La propiedad individual, vale decir, es el soporte anímico que garantiza la existencia del individuo en su ser carnal, afectivo, práctico y simbólico. Provisto de este soporte el sujeto, no sólo escapa (ilusoriamente) al dolor, al miedo y a la tristeza, 
protegiendo un cuerpo como propio; sino que además actúa en el mundo con la certeza de que su poder sobre las cosas y sobre los hombres se extenderá más allá de los límites de su cuerpo. $^{16}$

En una perspectiva similar Roberto Espósito (2003) comprende a la proprietas a partir de la dialéctica communitas-immunitas. La proprietas es lo que conserva a la individualidad del peligro de retornar a la nada en común (communitas); esto es, al extravío completo del sí mismo. En otras palabras, la propiedad es lo que salva al individuo de ser arrastrado al fondo inconsciente, caótico, traumático y mortal del que provenimos y que siempre aflora. Contra esa posibilidad el individuo se inmuniza (niega lo común) construyendo socialmente un orden de líneas y cercos que dividen los cuerpos para protegerlos de la amenaza de su desintegración. Con esto, la propiedad se presenta como el fundamento radical del individuo-en-el-mundo, tanto por tratarse del indicador histórico de un sujeto que es producido culturalmente en una relación de explotación (aspecto que Espósito omite), como por reflejar un modo de existencia cuyo nacimiento implica la expulsión de lo más primitivo: la muerte. ${ }^{17}$

Llegados aquí repitamos, entonces, que la propiedad debe ser entendida como algo más que un principio jurídico y un acto de apropiación; la propiedad es un dispositivo que fungió como soporte anímico para el hombre en el modo de producción capitalista. Dicho

\footnotetext{
${ }^{16}$ Sobre el componente "ilusorio/alusivo" de la ideología, véase Murillo (2008: 24-27).

17 Si bien coincidimos en los efectos ontológicos de esta constitución "inmunizante" del individuo moderno, nuestra principal discrepancia con la interpretación de Espósito radica en el procedimiento de encubrimiento ideológico que éste despliega. Espósito tiende a deducir las relaciones sociales de la etimología de los conceptos, lo que provoca dos consecuencias letales para su análisis. La primera, la deshistorización de esas relaciones efectivas de propiedad y sus modos de ser particulares en favor de una dialéctica trascendental entre lo propio y lo común; y la segunda, la confusión entre el lenguaje del "tener" y el acto de apropiación. De algún modo Espósito replica los mismos errores que Marx le señalara a Stirner: "Stirner - dice Marxrefutaba más arriba la abolición comunista de la propiedad privada convirtiendo la propiedad privada en el 'tener' y declarando luego el verbo 'tener' por una palabra indispensable, por una verdad eterna, ya que también en la sociedad comunista podría darse el caso de que él 'tuviera' dolores de vientre. Del mismo modo fundamenta aquí la imposibilidad de suprimir la propiedad privada, convirtiéndola en el concepto de la propiedad en general, explotando la relación etimológica entre la 'propiedad' y lo 'propio' y proclamando la palabra 'propio' como una verdad eterna, porque también bajo el régimen comunista puede darse el caso de que le sean 'propios' los dolores de vientre" (Marx, 2005: 264).
} 
dispositivo permitió integrar al individuo (despojado de sus medios de producción) al aparato productivo al producir a un sujeto capaz de relacionarse de manera exclusiva y excluyente con las cosas (con su fuerza de trabajo o con sus medios de producción). Un sujeto al que el dispositivo propietario proveyó de un lugar en el mundo, es decir, de una forma de organizar sus conductas con la esperanza de huir, en soledad, de la muerte.

\section{Palabras finales}

El trabajo se propuso reflexionar en torno a la propiedad privada en el capitalismo. El objetivo fue ofrecer algunos elementos teóricos para la elaboración de una analítica de este objeto. Partiendo de un breve diagnóstico acerca del estatuto actual de la propiedad en el marco de la ideología neoliberal, se identificaron dos supuestos teóricos de relevancia: en primer lugar, la universalización metafísica del objeto propiedad; y en segundo, la formulación de este principio como un garante ontológico.

En relación a lo primero, el trabajo justificó una vuelta a la crítica marxiana de la propiedad a la que entendimos como un acto de apropiación de una relación social de producción. Para Marx, la propiedad capitalista lejos está de ser una mera idea jurídica, el derecho de propiedad es antes bien un efecto ideológico de un acto de apropiación en una relación social de explotación. Así, la crítica de Marx permitió emplazar a la propiedad capitalista en el terreno histórico de las luchas (de clase) por la apropiación de los medios de existencia.

En relación al segundo supuesto contenido en la visión neoliberal de la propiedad, se verificó la necesidad de una analítica de este objeto que contemple, además de la instancia de apropiación (producción y reproducción de las condiciones materiales), la instancia de producción de un sujeto propietario. Para esto último, se propuso transitar en el escrito de las relaciones de propiedad al sujeto. Así, el recorrido se extendió desde la teoría althusseriana de los AIE y de la interpelación al concepto de dispositivo en Foucault. 
En una trayectoria que apuntaba a mostrar la presencia en la totalidad del modo de producción capitalista de un operador táctico-técnico específico que interviene en la fabricación de un sujeto propietario. A este operador lo denominamos dispositivo propietario, entendiendo por tal, un mecanismo que reúne elementos heterogéneos en la estrategia de producción de cuerpos propietarios; es decir, de sujetos que se relacionan de manera exclusiva y excluyente con las cosas.

No obstante el potencial teórico del concepto de dispositivo (por el que se ponen en evidencia una red de elementos en apariencia ajenos al fenómeno de la propiedad, pero que revelan ser la condición de posibilidad de las prácticas de apropiación), se procuró atender a una característica poco estudiada en él: su condición de soporte anímico. En efecto, para evitar malentendidos en torno al funcionamiento del dispositivo propietario, como aquel que llevaría a asociar a este mecanismo con un ejercicio de coerción "externa", omnipresente y determinante del sujeto, se intentó precisar una de sus características más notables: la de fungir de soporte anímico del sujeto. Esta característica consiste en involucrar al sujeto en el dispositivo a través de procesos de identificación con elementos que el mecanismo reúne. Los motivos de esta identificación por la que el sujeto adhiere a su propia sujeción, deben buscarse en la puesta en juego de su ser corporal, afectivo, práctico y simbólico; es decir, de su ser anímico. Esta es la razón por la que afirmamos que el dispositivo propietario no debe verse únicamente como un mecanismo "externo", sino como un soporte anímico para el hombre. En efecto, el dispositivo propietario funciona como un soporte para el individuo del modo de producción capitalista: el sujeto abraza al dispositivo para salvarse y allí mismo se implica en las prácticas de apropiación, dándose un lugar en el mundo. En ello radica, a nuestro juicio, el éxito ideológico del dispositivo propietario.

Por cierto, creemos que la teoría neoliberal de la propiedad logró imponer el sentido privado de la propiedad mediante un doble movimiento teórico: por un lado, aquel que extiende las fronteras de la propiedad (privada) más allá del orden jurídico, mostrando su omnipresencia como índice de todo comportamiento humano; y por el otro, aquel que 
sostiene que, sin la propiedad, peligraría nuestra existencia corporal, afectiva, práctica y simbólica. Lo primero, pues, destaca la importancia del concepto de dispositivo para una crítica de la propiedad; lo segundo, como ha de advertirse, su condición de soporte anímico.

\section{Bibliografía}

Alchian, Armen. 1965. "Some Economics of Property Rights". II Politico 30, vol. 30, n. 4, pp. 816829.

Althusser, Louis. 1988. Ideología y aparatos ideológicos de Estado. Nueva Visión, Buenos Aires.

Althusser, Louis. 2010. La revolución teórica de Marx. Siglo XXI, México.

Ariès, Philippe y Duby, George. 1991. Historia de la vida privada, vol. 6, Trotta, Madrid.

Balibar, Etienne. 2010. "Acerca de los conceptos fundamentales del materialismo histórico", en: Althusser L. y Balibar E., Para leer El capital. Siglo XXI, México. pp. 217-335.

Becker, Gary. 1962. "Investment in Human Capital: A Theoretical Analysis". The Journal of Political Economy, vol. 70, n. 5, pp. 9-49.

Butler, Judith. 2001. Mecanismos psíquicos del poder. Cátedra, Madrid.

Castel, Robert. 2010. El ascenso de las incertidumbres. FCE, Buenos Aires.

Coase, Ronald. 1937. "The Nature of the Firm, en Economica”. vol. 4, Issue 16, pp. 386-405.

Correas, Óscar. 2003. "Sobre la propiedad". Anuario de la Facultad de Derecho de la Universidad da Coruña, n. 7. pp. 207-231.

Davis, Ann. 2015. The Evolution of Property Relation. Palgrave Macmillan, New York.

Deleuze, Gilles. 1987. Foucault. Paidós, Barcelona.

Demsetz, Harold. 1967. "Toward a Theory of Property Rights". American Economic Review, vol. 57, n.2, pp. 347-359.

Derrida, Jacques. 2005. De la gramatología. Siglo XXI, México.

Dumont, Louis. 1987. Ensayos sobre el individualismo. Alianza, Madrid.

Engels, Friedrich y Marx, Karl. 2005. Ideología alemana. Santiago Rueda Editores, Buenos Aires.

Epstein, Richard. 1985. Takings: Private Property and the Power of Eminent Domain. Harvard University Press, Cambridge. 
Espósito, Roberto. 2003. Communitas. Amorrortu, Buenos Aires.

Espósito, Roberto. 2006. Bíos. Amorrortu, Buenos Aires.

Foucault, Michel. 1984. "El juego de Michel Foucault", en: Michel Foucault, Saber y verdad, La Piqueta, Madrid. pp. 127-162.

Foucault, Michel. 2008a. Defender la sociedad. FCE, Buenos Aires.

Foucault, Michel. 2008b. Vigilar y castigar. Siglo XXI, Buenos Aires.

Foucault, Michel. 2009. Historia de la sexualidad, La voluntad del saber. Siglo XXI, Buenos Aires.

Fromm, Erich. 2007. Del tener al ser. Paidós, Barcelona.

Harris, James. 2003. Property and justice. Oxford University Press, Oxford.

Hayek, Friedrich. 1981. "El liberalismo", en: Nuevos Estudios, Eudeba, Buenos Aires. pp. 105-130.

Hayek, Friedrich. 1990. La fatal arrogancia. Unión Editorial. Madrid.

Hegel, Friedrich. 1999. Principios de la filosofía del derecho. Edhasa, Barcelona.

Honoré, Antony. 1961. "Ownership", en A. G. Guest (ed.), Oxford Essays in Jurisprudence. Oxford University Press, Oxford.

Jameson. Fredric. 1996. Teoría de la posmodernidad. Trotta, Madrid.

Landes, David. 1998. The Wealth and Poverty of Nations. W. W. Norton \& Company, New York.

Lemke, Thomas. 2006. "'Marx sin comillas'”: Foucault, la gubernamentalidad y la crítica del neoliberalismo", en Lemke, Thomas et. al. Marx y Foucault, Nueva Visión, Buenos Aires. pp. 5-20.

Lepage, Henri. 1986. Por qué la propiedad. Instituto de Estudios Económicos, Madrid.

Macpherson, Crawford. 1970. La teoría política del individualismo posesivo: de Hobbes a Locke. Fontanella, Barcelona.

Marx, Karl. 1970. Miseria de la filosofía. Siglo XXI, México.

Marx, Karl. 2004. El capital. Siglo XXI, Buenos Aires.

Marx, Karl. 2007. Los debates de la Dieta Renana. Gedisa, Barcelona.

Marx, Karl. 2009. Grundrisse. Siglo XXI, México.

Marx, Karl. 2010. Manuscritos económico-filosóficos de 1844. Colihue, Buenos Aires.

Mises, Ludwig von. 1986. La acción humana. Unión Editorial, Madrid.

Munzer, Stephen. 1990. A Theory of Property. Cambridge University Press, Cambridge. 


\section{Leviathan | Cuadernos de Investigación Política}

LAGARRIGUE, F. M. "El dispositivo propietario. Elementos para una analítica de la propiedad"

Murillo, Susana. 2008. Colonizar el dolor. La interpelación ideológica del Banco Mundial en América Latina. El caso argentino desde Blumberg a Cromañón. CLACSO, Buenos Aires.

North, David. 1973. The Rise of the Western World: A New Economic History, Cambridge University Press, Cambridge.

Nozick, Robert. 1988. Anarquía, Estado y utopía. FCE, México.

Pateman, Carole. 2002. "Self-Ownership and Property in the Person: Democratization and a Tale of Two Concepts". The Journal of Political Philosophy, vol. 10, issue 1, pp. 20-53.

Pipes, Richard. 1999. Propiedad y libertad. FCE, México.

Plant, Arnold. 1934. "The Economic Theory Concerning Patents for Inventions", Economica, vol. 1, n. 1, pp. 30-51.

Proudhon, Joseph. 1983. ¿Qué es la propiedad? Ediciones Orbis, Madrid.

Schultz, Theodore. 1961. "Investment in Human Capital", The American Economic Review, vol. 51, n. 1, pp. 1-17.

Singer, Joseph. 2000. Entitlement. The Paradoxes of Property. Yale University Press, New Haven.

Stirner, Max. 2007. El Único y su propiedad. Reconstruir, Buenos Aires.

Revisado por Maria Cecília Ípar

Tramitación del artículo:

Sometido: 10/10/2017

Revisiones requeridas: 28/11/2017

Versión corregida: 1/12/2017

Aceptado: 3/12/2017 